\title{
Comparative Study of Estimatives and Experimental Published Results of Spark Ignition Engine Performance using Different Fuels.
}

\author{
Barbara N. Aud ${ }^{1}$, Th5ag6 A. L. Silva ${ }^{1}$, Moilton R. Franco Júnior ${ }^{*}$, NattaciaR. A. F. \\ Rocha $^{2}$, Nadinne P. Merlo ${ }^{2}$ and Warley A. Pereira ${ }^{2}$ \\ ${ }^{1}$ Post-Graduation Program in Biofuels - UFU - Federal University of Uberlândia. 2121 João Naves de Avila- \\ Minas Gerais- Brazil \\ ${ }^{2}$ UniRV-Rio Verde University - Fazenda Fontes do Saber-Rio Verde - Goiás Brazil
}

*Corresponding Author: Moilton R. Franco Júnior, Post-Graduation Program in Biofuels - UFU Federal University of Uberlândia. 2121 João Naves de Avila-Minas Gerais- Brazil

\begin{abstract}
This study consists of comparing the experimental thermal efficiency in spark ignition engines with the mathematical modeling analysis. As renewable energy source ethanol, due to the high octane number, low emissions and high engine performance is preferred alternative fuel. First stage of this study, etanol, gasoline and blends of them (E22 and E50) were fuels used for the three authors in the tests in a single cylinder, fourstrokespark ignition and fuel injection engine.

In the mathematical modeling analysis, it was used ideal and virial equation to represent pVT behavior of the gas in the Otto cycle. Then, for each calculation path proposed, the engine thermal efficiency was determinedon the variation of compression ratio for two different inlet temperature.

In order to test the methodology used, limited experimental measurements were used and test data. The best method was the one which considered the influence of temperature in the Poison Coefficient. As seen from the results of pVT equations in the mathematical modeling, the calculated engine thermal effciency did not vary substantially using ideal or virial equation.
\end{abstract}

Keywords: fuels; experimental; calculated; thermal efficiency; Otto cycle.

\section{INTRODUCTION}

The efficiency of a modern spark ignition port injection (SIPI) engine is limited by a number of factors, includinglosses by cooling and friction. Generally, the efficiency of these engines is determined by the compression ratio (the ratio between the minimum and maximum volumes of the combustion chamber). Typical efficiencies for these engines are on the order of $20 \%$.

Spark ignition direct injection (SIDI) engines may bring a major improvement in SI engines because of their potential reduction in fuel consumption. However, for compliance with stringent emissions standards while performing at highefficiency levels, this engine requires further development, including advanced exhaust treatment and low sulfur fuel compatible with its operating characteristics.Other improvements to thermal efficiency for these engines result from the exhaust gases having a composition much closer to that of air and a lower temperature (which reduces heat loss) and the induction of excess air reduces pumping losses.In this last case, it is important to mention that Ostrikov et al., 2018 [1] developed a technological process and a flushing composition flushing oil for cleaning lubricating system of tractor diesel engines. Also, Buratsev et al, 2018 [2] working with turbulent combustion of natural gas have observed that the increasinge in the calorific intensity of the combustion chamber of one reactor as a result of a decrease in its volume leads to full conversion of the starting reagents and to lower carbon-black formation, then this remark ought to be applied to the combustion chambre of the engines.

Some typical observations were done by Agarwal, 2007 [3] from the engine tests suggested that the thermal efficiency of the engine generally improves, cooling losses and exhaust gas temperature increase, smoke opacity generally gets lower for biodiesel blends. Possible reason may be additional 
lubricity properties of the biodiesel; hence reduced frictional losses (FHP). The energy thus saved increases thermal efficiency, cooling losses and exhaust losses from the engine. The thermal efficiency starts reducing after a certain concentration of biodiesel. Knowing a model for engine working would help to obtain those observations decreasing such experimental labour.

The effect of biofuels (metanol, etanol and butanol) on internal combustion engine performance and exaust emissions was recently studied by Peng, 2018 [4]. In the similar way, Natarajan et al., 2018 [5] worked with engine performance and emission characteristics of ethanol and diesel blends. Tests were carried out in a DI compression ignition engine. In order to search for the optimal process response through a limited number of experiment runs, application of Taguchi method in combination with grey relational analysis[6,7] was applied for solving amultiple response optimisation problem. Finally, solid carbon fuel was used by Glazov et al., 2018 [8 ] in the case of a superadiabatic filtration combustion mode, the combustion velocity was primarily determined by the supply rate of the oxidizing agent and by the stoichiometric process ratio for particular conditions.

The aim of present study proposes a new approach based on Otto Cycle to determine the thermal efficiency and to compare to the experimental data published. Using mathematical models for quantitative estimative of the efficiency demands to engine quality specification is the perspective way for simplifying costs and setting norms. This study consists of fourmethodologies applied to two different gaseous systems. In order to test the methodologies, limited experimental measurements were used as testing data. In addition, it is believe that the engine thermal efficiency will decrease substantially when considering the effect of temperature in the methodologies.

\section{Methodology}

In the combustion engine, heat $\left(Q_{q}^{\text {air }}\right)$ is added at constant volume while the piston is momentarily at rest at head-end dead center. Then, the first law gives,

$Q_{q}^{\text {air }}=N . C_{v, q}^{\text {air }}\left(T_{3}-T_{2}\right)$

Where $C_{v, q}^{a i r}$ is the molar heat capacity at constant volume of the air calculated by mixture rule found in Poling et al, 2001 [9] and $T_{2}$ and $T_{3}$ are the intake gas temperature at the inlet and outlet of the compressor, respectively. The rejection of heat $\left(Q_{f}^{\text {air }}\right)$ from the air while the piston is at crank-end dead center can be calculated by the first law as follows,

$Q_{f}^{a i r}=N . C_{v, f}^{a i r}\left(T_{4}-T_{1}\right)$

Where $C_{v, f}^{a i r}$ is the molar heat capacity at constant volume of the air calculated by mixture rule found in Poling et al, 2001 [9] and $T_{1}$ and $T_{4}$ are the intake gas temperature at the outlet and inlet of the scape gases engine system, respectively.

$\eta=1-\frac{C_{v, q}^{a i r}\left(T_{4}-T_{1}\right)}{C_{v, f}^{a i r}\left(T_{3}-T_{2}\right)}$

Then, the thermal efficiency $(\eta)$ of this cycle is found as follows, assuming constant molar heat capacity of air as ideal gas:

$\eta=1-\frac{T_{4}-T_{1}}{T_{3}-T_{2}}$

Equations of ideal gas for the isentropic process can be presented:

$T V^{k-1}=\operatorname{cte}(5.1) T p^{1-k / k}=\operatorname{cte}(5.2) p V^{k}=\operatorname{cte}(5.3)$

Where $\mathrm{k}$ is the Poisson coefficient calculated by $k=C_{p}^{\text {air }} / C_{v}^{\text {air }}$.

If the virial equation $[10,11]$ is representing the volumetric gas behavior, and $B$ is the second virial coefficient that is a function of temperature. Then, the isentropic process has to be represented by the following energy balance:

$\frac{C_{v, m}^{a i r}}{R} \frac{d T}{T}=\frac{T(d B / d T) d V}{(V-B)^{2}}+\frac{d V}{V-B}$

This equation has to be integrated when the system goes from state 1 to state 2 , and from 3 to 4 as well. Assumptions of molar heat capacity at constant volume, average temperature, $B$ and its derivative are all considered to be the average values in the range of integrated temperature will be used resulting: 
Comparative Study of Estimatives and Experimental Published Results of Spark Ignition Engine Performance using Different Fuels.

$-\frac{C_{v}}{R} \ln \frac{T_{2}}{T_{1}}=-2 \bar{T} \frac{\overline{d B}}{d T}\left(\frac{1}{\left(V_{2}-\bar{B}\right)^{3}}-\frac{1}{\left(V_{1}-\bar{B}\right)^{3}}\right)+\ln \frac{V_{2}-\bar{B}}{V_{1}-\bar{B}}$

In what, considering that the average values $\left(\frac{\bar{d}}{d T}, \bar{B}, \bar{T}\right)$ for each process are calculated doing the arithmetic mean of initial and end of process.

The second virial coefficient $(B)$ was estimated by Vetere's model [10]. Also, considering that in the Otto cycle, the process fluid can be composed by (1) ambient air: a mixture of $\mathrm{O}_{2}$ and $\mathrm{N}_{2}$ or (2) combustion gas: a mixture of $\mathrm{H}_{2} \mathrm{O}, \mathrm{CO}_{2}$ and $\mathrm{N}_{2}$, the second virial of the mixture $\left(B_{M}\right)$ was calculated by the following equation:

$B_{M}=\sum_{i=1}^{N} \sum_{j=1}^{N} x_{i} x_{i} B_{i j}$

Where $\mathrm{N}$ is the number of compounds and $i, j$ are the compounds of the mixture.

In this work, four methods or path of calculations were used to estimate the thermal efficiency of the engine, as follows:

Method 1: The system was considered as ideal gas and there was no influence of temperature on the properties in the calculations;

Method 1.1: The system was considered as ideal gas and the influence of temperature was regarded on the properties in the calculations;

Method 2: The system was considered as virial gas and there was no influence of temperature on the properties in the calculations;

Method 2.1: The system was considered as virial gas and the influence of temperature was regarded on the properties in the calculations;

Determination of relative deviation (R.D.):

The relative deviation between experimental $\left(\eta^{\text {exp }}\right)$ and calculated $\left(\eta_{\text {met. }}^{\text {calc }}\right)$ thermal effciency was determined using the formula stated in Equation (1).

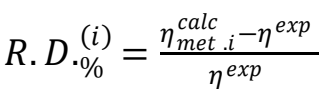

Where $i$ is the method used to estimate the thermal efficiency.

Table1. Experimental thermal efficiency as a function of compression ratio, published and calculated by four methods using [system 1: $\mathrm{O}_{2} / \mathrm{N}_{2}$ ] ambiente air as type of system. (Costa and Sodré, 2011[12] = $P_{1}: 0.898 \mathrm{~atm}$ e $T_{1}: 293 \mathrm{~K}$; Sudarmanta et al., 2016[13] and Balki and Sayin, 2014[14] $=P_{1}: 1$ atm e $T_{1}: 300 \mathrm{~K}$ ).

\begin{tabular}{|c|c|c|c|c|c|c|c|c|}
\hline Reference & $\mathrm{r}$ & \%ethanol & $\%$ gasoline & $\eta^{\text {exp }}$ & $\eta_{\text {met .1 }}^{\text {calc }}$ & $R . D_{\%}^{(1)}$ & $\eta_{\text {met.1.1 }}^{\text {calc }}$ & $R . D_{0 \%}^{(1.1)}$ \\
\hline \multirow{6}{*}{$\begin{array}{l}\text { Costa and } \\
\text { Sodré, } 2011\end{array}$} & \multirow{3}{*}{10} & 100 & 0 & 34.70 & 60.01 & 73.20 & 46.04 & 32.68 \\
\hline & & 22 & 78 & 34.30 & 60.01 & 74.96 & 46.04 & 34.23 \\
\hline & & 100 & 0 & 35.60 & 61.49 & 72.72 & 47.39 & 33.12 \\
\hline & 11 & 22 & 78 & 35.00 & 61.49 & 75.69 & 47.39 & 35.40 \\
\hline & \multirow[b]{2}{*}{12} & 100 & 0 & 37.20 & 62.80 & 68.82 & 48.59 & 30.62 \\
\hline & & 22 & 78 & 34.80 & 62.80 & 80.46 & 48.59 & 39.63 \\
\hline \multirow{4}{*}{$\begin{array}{l}\text { Sudarmanta } \\
\text { et al., } 2016\end{array}$} & \multirow[b]{2}{*}{9.6} & 0 & 100 & 41.50 & 59.35 & 43.01 & 45.39 & 4.55 \\
\hline & & 50 & 50 & 31.50 & 59.35 & 88.41 & 45.39 & 44.10 \\
\hline & 10.6 & 50 & 50 & 33.50 & 60.92 & 81.85 & 46.83 & 39.79 \\
\hline & 11.6 & 50 & 50 & 36.00 & 62.30 & 73.06 & 48.07 & 33.53 \\
\hline \multirow{8}{*}{$\begin{array}{c}\text { Balki and } \\
\text { Sayin, } 2014\end{array}$} & \multirow[b]{2}{*}{8} & 100 & 0 & 28.20 & 56.29 & 99.61 & 42.68 & 51.35 \\
\hline & & 0 & 100 & 23.90 & 56.29 & 135.52 & 42.68 & 78.58 \\
\hline & \multirow[b]{2}{*}{8.5} & 100 & 0 & 29.60 & 57.33 & 93.68 & 43.56 & 47.16 \\
\hline & & 0 & 100 & 29.20 & 57.33 & 96.34 & 43.56 & 49.18 \\
\hline & \multirow[b]{2}{*}{9} & 100 & 0 & 30.10 & 58.29 & 93.65 & 44.43 & 47.61 \\
\hline & & 0 & 100 & 29.80 & 58.29 & 95.60 & 44.43 & 49.09 \\
\hline & \multirow[b]{2}{*}{9.5} & 100 & 0 & $\begin{array}{l}30.30 \\
\end{array}$ & 59.18 & 95.31 & 45.24 & 49.31 \\
\hline & & 0 & 100 & 27.00 & 59.18 & 119.19 & 45.24 & 67.56 \\
\hline \multirow[t]{3}{*}{ Reference } & $\mathrm{r}$ & \%ethanol & $\%$ gasoline & $\eta^{\exp }$ & $\eta_{\text {met .2 }}^{\text {calc }}$ & $R . D{ }_{\%}^{(2)}$ & $\eta_{\text {met } 2.1}^{\text {calc }}$ & R.D. $\%$ \\
\hline & \multirow[b]{2}{*}{10} & 100 & 0 & 34.70 & 60.16 & 73.37 & 47.19 & 35.99 \\
\hline & & 22 & 78 & 34.30 & 60.16 & 75.39 & 47.19 & 37.58 \\
\hline
\end{tabular}


Comparative Study of Estimatives and Experimental Published Results of Spark Ignition Engine Performance using Different Fuels.

\begin{tabular}{|c|c|c|c|c|c|c|c|c|}
\hline \multirow{4}{*}{$\begin{array}{c}\text { Costa and } \\
\text { Sodré, } 2011\end{array}$} & \multirow[b]{2}{*}{11} & 100 & 0 & 35.60 & 61.66 & 73.20 & 48.86 & 37.25 \\
\hline & & 22 & 78 & 35.00 & 61.66 & 76.17 & 48.86 & 39.60 \\
\hline & \multirow[b]{2}{*}{12} & 100 & 0 & 37.20 & 62.99 & 69.33 & 49.95 & 34.27 \\
\hline & & 22 & 78 & 34.80 & 62.99 & 81.01 & 49.95 & 43.53 \\
\hline \multirow{4}{*}{$\begin{array}{c}\text { Sudarmanta } \\
\text { et al., } 2016\end{array}$} & \multirow[b]{2}{*}{9.6} & 0 & 100 & 41.50 & 59.52 & 43.42 & 46.59 & 12.27 \\
\hline & & 50 & 50 & 31.50 & 59.52 & 88.95 & 46.59 & 47.90 \\
\hline & 10.6 & 50 & 50 & 33.50 & 61.10 & 82.39 & 48.35 & 44.33 \\
\hline & 11.6 & 50 & 50 & 36.00 & 62.49 & 73.58 & 49.46 & 37.39 \\
\hline \multirow{8}{*}{$\begin{array}{c}\text { Balki and } \\
\text { Sayin, } 2014\end{array}$} & \multirow[b]{2}{*}{8} & 100 & 0 & 28.20 & 56.43 & 100.11 & 43.61 & 54.65 \\
\hline & & 0 & 100 & 23.90 & 56.43 & 136.11 & 43.61 & 69.91 \\
\hline & \multirow[b]{2}{*}{8.5} & 100 & 0 & 29.60 & 57.48 & 94.19 & 44.63 & 50.78 \\
\hline & & 0 & 100 & 29.20 & 57.48 & 96.85 & 44.63 & 52.84 \\
\hline & \multirow[b]{2}{*}{9} & 100 & 0 & 30.10 & 58.45 & 94.19 & 45.74 & 51.96 \\
\hline & & 0 & 100 & 29.80 & 58.45 & 96.14 & 45.74 & 53.49 \\
\hline & \multirow[b]{2}{*}{9.5} & 100 & 0 & 30.30 & 59.35 & 95.87 & 46.45 & 53.30 \\
\hline & & 0 & 100 & 27.00 & 59.35 & 119.81 & 46.45 & 72.04 \\
\hline
\end{tabular}

- The methodologies using the ideal gas model and gas with the second virial coefficient, when taking into account the influence of the temperature in the process, provided the smallest relative deviations for the thermal efficiency when compared to the deviations obtained by the methodologies in which the influence of the temperature was not considered.

- Comparing the ideal gas and gas with the second virial coefficient methodologies, with the same consideration regarding the influence or not of the temperature in the process, it was perceived that the relative deviations for the thermal efficiency are very similar.

- For all technical articles studied, it was observed that the use of the ideal gas model, influenced by temperature (met.1.1), provided the lowest relative deviations when compared to the other three methodologies studied.

- The relative deviations between the experimental and estimated methodologies used in this paper for the article by Balki and Sayin (2014) were always greater than the deviations found for the other two articles studied.

All Figures 1-5 were built to present the results obtained using the method 1.1 where the effect of temperature was considered.

Table2. Experimental thermal efficiency, as a function of compressionratio,published and calculated by four methods using [system 2: $\mathrm{CO}_{2} / \mathrm{N}_{2} / \mathrm{H}_{2} \mathrm{O}$ ] combustion gases as type of system.

\begin{tabular}{|c|c|c|c|c|c|c|c|c|}
\hline Reference & $\mathrm{r}$ & \%ethanol & $\%$ gasoline & $\eta^{\exp }$ & $\eta_{\text {met } 1}^{\text {calc }}$ & $R . D{ }_{\%}^{(1)}$ & $\eta_{\text {met.1.1 }}^{\text {calc }}$ & $R \cdot D_{\%}^{(1.1)}$ \\
\hline \multirow{6}{*}{$\begin{array}{c}\text { Costa and } \\
\text { Sodré, } \\
2011\end{array}$} & \multirow[b]{2}{*}{10} & 100 & 0 & 34.70 & 55.89 & 61.07 & 46.54 & 34.12 \\
\hline & & 22 & 78 & 34.30 & 56.32 & 64.19 & 46.90 & 36.73 \\
\hline & \multirow[b]{2}{*}{11} & 100 & 0 & 35.60 & 57.30 & 60.96 & 47.46 & 33.31 \\
\hline & & 22 & 78 & 35.00 & 57.73 & 64.94 & 47.83 & 36.66 \\
\hline & \multirow[b]{2}{*}{12} & 100 & 0 & 37.20 & 58.53 & 57.34 & 48.27 & 29.76 \\
\hline & & 22 & 78 & 34.80 & 58.97 & 69.45 & 48.70 & 39.94 \\
\hline \multirow{4}{*}{$\begin{array}{l}\text { Sudarmanta } \\
\text { et al., } 2016\end{array}$} & \multirow[b]{2}{*}{9.6} & 0 & 100 & 41.50 & 55.68 & 34.17 & 47.30 & 13.98 \\
\hline & & 50 & 50 & 31.50 & 55.67 & 76.73 & 47.21 & 49.87 \\
\hline & 10.6 & 50 & 50 & 33.50 & 57.16 & 70.63 & 47.42 & 41.55 \\
\hline & 11.6 & 50 & 50 & 36.00 & 58.47 & 62.42 & 49.05 & 36.25 \\
\hline \multirow{8}{*}{$\begin{array}{c}\text { Balki and } \\
\text { Sayin, } 2014\end{array}$} & \multirow[b]{2}{*}{8} & 100 & 0 & 28.20 & 52.38 & 85.74 & 43.02 & 52.55 \\
\hline & & 0 & 100 & 23.90 & 52.78 & 120.84 & 43.37 & 81.46 \\
\hline & \multirow[b]{2}{*}{8.5} & 100 & 0 & 29.60 & 53.36 & 80.27 & 44.86 & 51.55 \\
\hline & & 0 & 100 & 29.20 & 53.77 & 84.14 & 44.03 & 50.79 \\
\hline & \multirow[b]{2}{*}{9} & 100 & 0 & 30.10 & 54.26 & 80.27 & 45.43 & 50.93 \\
\hline & & 0 & 100 & 29.80 & 54.68 & 83.49 & 46.63 & 56.47 \\
\hline & \multirow[b]{2}{*}{9.5} & 100 & 0 & 30.30 & 55.10 & 81.85 & 45.95 & 51.65 \\
\hline & & 0 & 100 & 27.00 & 55.52 & 105.63 & 47.19 & 74.78 \\
\hline \multirow[t]{3}{*}{ Reference } & $\mathrm{r}$ & \%ethanol & $\%$ gasoline & $\eta^{\exp }$ & $\eta_{\text {met } .2}^{\text {calc }}$ & R.D. ${ }^{(2)}$ & $\eta_{\text {met } 2.1}^{\text {calc }}$ & $R . D .{ }_{0}^{(2.1)}$ \\
\hline & \multirow{2}{*}{10} & 100 & 0 & 34.70 & 56.43 & 62.62 & 47.87 & 37.95 \\
\hline & & 22 & 78 & 34.30 & 56.79 & 65.57 & 48.03 & 40.03 \\
\hline
\end{tabular}


Comparative Study of Estimatives and Experimental Published Results of Spark Ignition Engine Performance using Different Fuels.

\begin{tabular}{|c|c|c|c|c|c|c|c|c|}
\hline \multirow{4}{*}{$\begin{array}{c}\text { Costa and } \\
\text { Sodré, } \\
2011\end{array}$} & \multirow[b]{2}{*}{11} & 100 & 0 & 35.60 & 57.87 & 62.56 & 49.18 & 38.15 \\
\hline & & 22 & 78 & 35.00 & 58.24 & 66.40 & 49.34 & 40.97 \\
\hline & \multirow[b]{2}{*}{12} & 100 & 0 & 37.20 & 59.14 & 58.98 & 51.78 & 39.19 \\
\hline & & 22 & 78 & 34.80 & 59.51 & 71.01 & 52.14 & 49.83 \\
\hline \multirow{4}{*}{$\begin{array}{l}\text { Sudarmanta } \\
\text { et al., } 2016\end{array}$} & \multirow[b]{2}{*}{9.6} & 0 & 100 & 41.50 & 56.21 & 35.45 & 47.61 & 14.72 \\
\hline & & 50 & 50 & 31.50 & 56.13 & 78.19 & 47.50 & 50.79 \\
\hline & 10.6 & 50 & 50 & 33.50 & 57.66 & 72.12 & 48.34 & 44.30 \\
\hline & 11.6 & 50 & 50 & 36.00 & 58.99 & 63.86 & 49.83 & 38.42 \\
\hline \multirow{8}{*}{$\begin{array}{c}\text { Balki and } \\
\text { Sayin, } 2014\end{array}$} & \multirow[b]{2}{*}{8} & 100 & 0 & 28.20 & 52.87 & 87.48 & 45.21 & 60.32 \\
\hline & & 0 & 100 & 23.90 & 53.25 & 122.80 & 45.53 & 90.50 \\
\hline & \multirow[b]{2}{*}{8.5} & 100 & 0 & 29.60 & 53.87 & 81.99 & 45.75 & 54.56 \\
\hline & & 0 & 100 & 29.20 & 54.26 & 85.82 & 46.12 & 57.95 \\
\hline & \multirow[b]{2}{*}{9} & 100 & 0 & 30.10 & 54.79 & 82.03 & 46.50 & 54.49 \\
\hline & & 0 & 100 & 29.80 & 55.19 & 85.20 & 47.01 & 57.75 \\
\hline & \multirow[b]{2}{*}{9.5} & 100 & 0 & 30.30 & 55.65 & 83.66 & 46.99 & 55.08 \\
\hline & & 0 & 100 & 27.00 & 56.05 & 107.59 & 47.52 & 76.00 \\
\hline
\end{tabular}

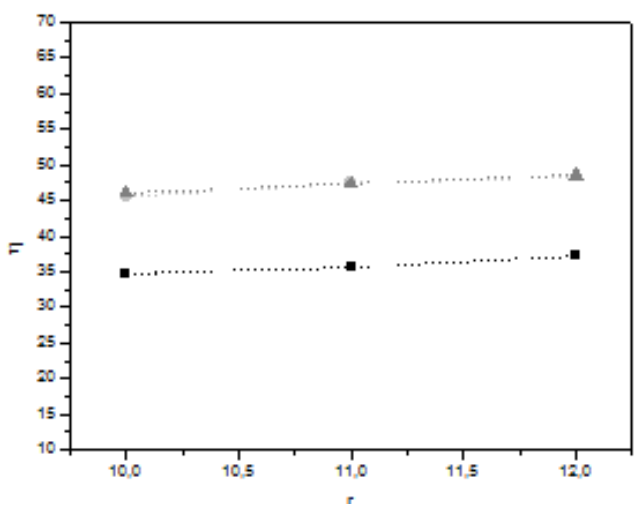

Figure1. Comparison of experimental thermal efficiency at variation compressionratio and type of system. (Costa and Sodré, 2011 - burnt ethanol, Systeml ( ), System 2 ( ) ).

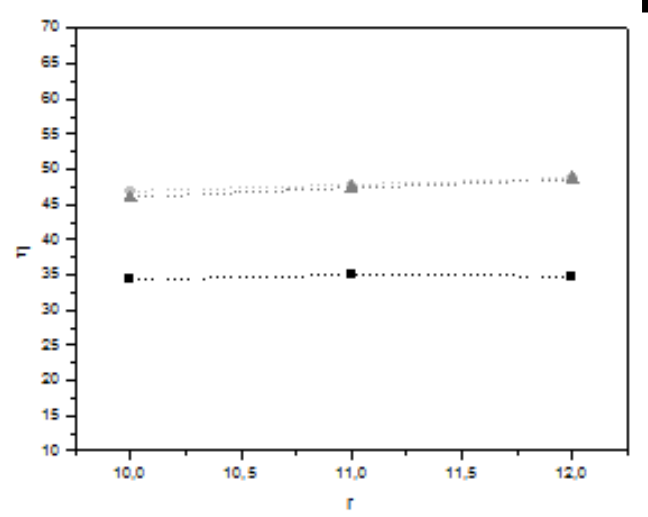

Figure2. Comparison of experimental thermal efficiency at variation compression ratio and type of system. $(\square$ Costa and Sodré, 2011 - burnt E22,System $2(-\nabla)$, System $1-$ ).

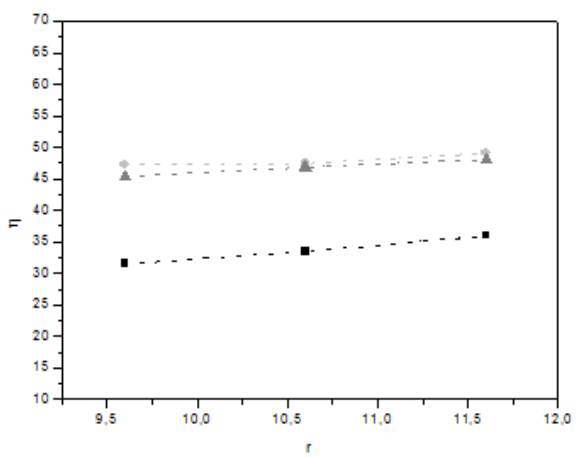

Figure3. Comparison of experimental thermal efficiency at variation compression ratio and type of system. $(\triangle$ Sudarmanta et al. (2016) - burnt E50, System 1 $\odot)$, System $2(\square))$. 


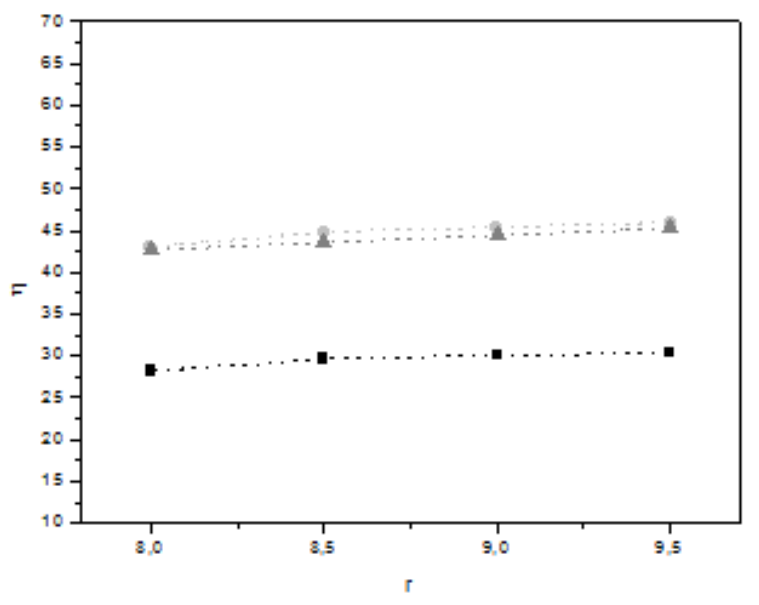

Figure4. Comparison of experimental thermal efficiency at variation compression ratio and type of system. ( $\square$ Balki and Sayin, 2014 - burnt ethanol, System 1(๑), System $2(\square)$ ).

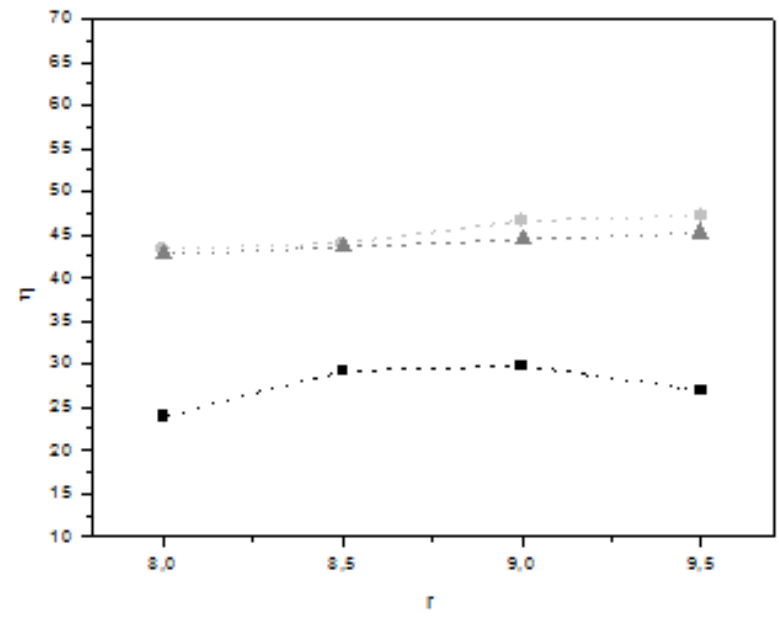

Figure5. Comparison of experimental thermal efficiency at variation compression ratio and type of system. ( $\square$ Balki and Sayin, 2014 - burnt gasoline, System $1(-)$ ), System $2(\square)$ ).

\section{CONCLUSiON}

All calculations path to estimate thermal efficiency of the engine showed no significant variationwith ideal and virial equation to represent $\mathrm{pVT}$ gas behavior. However, when the variation in $\mathrm{k}$ coefficient was regarded, virial equation yielded a little high result for thermal efficiency of the engine thanideal equation. Differently from the literature, there are no maximum thermal efficiencies obtained for alltested fuels and for all compression ratios, then the modeling quality has to be improved.

The engine thermal efficiency rose up increasing compression ratioup to 20:1 with all fuel. At the higher compression ratiosthe thermal efficiency did not vary noticeably.

The most important advantage of the mathematical approach is that it can be used the better methodology for the design and optimization of new, novel or more complicated systems, which are being researched experimentaly in laboratory. So, engineering effortcan be reduced in the areas.

Concerning about the gaseous system, there are no advantages of the use of combustion gases $\left(\mathrm{N}_{2}\right.$, $\left.\mathrm{CO}_{2}, \mathrm{H}_{2} \mathrm{O}\right)$ compared to classical method $\left(\mathrm{O}_{2}, \mathrm{~N}_{2}\right)$ which has simplicity and capacity to provide similar quality results and also do not require more experimental study.

\section{REFERENCES}

[1] Ostrikov, V. V., Vigforovich, V. I., Safonov, V. V. and Kartoshken, A. P.,Chem. and Tech. of Fuels and Oils, 2018, vol. 54, no. 1, pp. 24-28.

[2] Buravtsev, N. N.,Kolbanovskii, Y. A., Rossikhin,I. V. and Bilera, I. V.,Russian Journal of Applied Chemistry,2018, Vol. 91, no. 10, pp. 1588-1596. 
Comparative Study of Estimatives and Experimental Published Results of Spark Ignition Engine Performance using Different Fuels.

[3] Agarwal, A. K.,Progress in Energy and Combustion Science, 2007, vol. 33, pp. 233-271.

[4] Peng, D.-X.,Chemistry and Technology of Fuels and Oils, 2018, Vol. 54, no. 1, pp. 29-36.

[5] Natarajan, S., Pitchandi, K., Mahalakshmi, N.V.,Journal of Thermal Science,2018, Vol.27, no.1, pp. 8994.

[6] Pohit, G.\&Misra, D.,Journal of Engineering,Hindawi, 2013, pp.1-8.

[7] Krishnaiah, K.\& Shahabudeen, P., Applied Designof Experiments and Taguchi methods, PHI LearningPrivate Limited, New Delhi, India, ISBN: 978-81-203-4525-0, pp. 273-284, 2012.

[8] Glazov, S. V., Kislov,V. M. and Salgansky, E. A.,Russian Journal of Applied Chemistry, 2018,Vol. 91, No. 10,pp. 1581-1587.

[9] Poling, B. E., Prausnitz, J. M., O'Connell, J. P.,The properties of gases and liquids $5^{\text {th }}$ ed. McGraw-Hill, $2001-768$ pgs

[10] Vetere, A., Fluid Phase Equilibria,2005, vol. 230, no. 1-2, pp. 15-20.

[11] Meng, L., Duan, Y.-Y., Fluid Phase Equilibria, 2007,vol. 258, pp. 29-33.

[12] Costa, R. C., Sodré, J. R.,Applied Thermal Engineering, 2011, vol. 31, no. 2-3, pp. 278-283.

[13] Sudarmanta, B.,B. Junipitoyo, B.,Putra, A. B. K. and Sutantra, I N., ARPN Journal of Engineering and Applied Sciences,2016, vol. 11, no. 4, pp. 2768-2774.

[14] Balki, M. K., Sayin, C., Energy, 2014, vol. 71, pp. 194-201.

Citation: Moilton R. Franco Júnior, et.al, "Comparative Study of Estimatives and Experimental Published Results of Spark Ignition Engine Performance using Different Fuels.", International Journal of Advanced Research in Chemical Science, vol. 6, no. 11, p. 33-39, 2019. DOI: http://dx.doi.org/10.20431/23490403.0611003

Copyright: (c) 2019 Authors. This is an open-access article distributed under the terms of the Creative Commons Attribution License, which permits unrestricted use, distribution, and reproduction in any medium, provided the original author and source are credited. 